\title{
Visual outcome and prognostic factors after magnetic extraction of posterior segment foreign bodies in 40 cases
}

\author{
C Chiquet, J C Zech, P Gain, P Adeleine, C Trepsat
}

\begin{abstract}
Aims-To evaluate the clinical features as well as the visual and anatomical outcome in eyes with magnetic posterior segment foreign bodies, to identify prognostic factors after removal using an electromagnet.

Methods-The records of 40 patients with posterior segment foreign bodies were retrospectively reviewed for 6 years (198994). Post-traumatic cataracts and secondary retinal detachments were treated using conventional surgical techniques. Pars plana vitrectomy was used only for late complications. The mean follow up was 30 months (6-71). Clinical factors were studied using univariate analysis.

Results-The most common findings before treatment of these 40 eyes were lens wound, hyphaema, vitreous haemorrhage, and retinal impairment. The foreign body was in the vitreous $(85 \%)$ or minimally embedded in the retina $(15 \%)$. Initial visual acuity was worse or equal to $20 / 40$ in $70 \%$ of the cases. Subsequent to surgical treatment, a cataract was reported in $60 \%$ of the patients. Postoperative complications included retinal detachment (15\%) and phthysis (5\%). The prognosis was worse in cases with intraocular foreign body of largest diameter $\geqslant 3 \mathrm{~mm}$, an initial visual acuity less than $20 / 200$, or the presence of post-traumatic retinal detachment. Presence of initial intravitreous haemorrhage, hyphaema, or intraocular tissue prolapse did not appear to affect the prognosis.
\end{abstract}

Conclusion-The long term visual acuity results indicated that wound repair associated with conventional magnet extraction in an emergency is a viable treatment for posterior segment magnetic foreign bodies in this selected group. At the time of diagnosis, size of foreign body ( $<3 \mathrm{~mm}$ ) and initial visual acuity $\geqslant 20 / 200$ were predictors of good visual outcome after primary magnetic extraction.

(Br F Ophthalmol 1998;82:801-806)

Intraocular foreign bodies (IOFB) are a major cause of ocular trauma and the most serious problem is the resulting impairment of visual function. Young adults, especially men, are the most likely victims of industrial and agricultural injuries. In recent years, magnetic extraction has been criticised whereas vitrectomy with removal by forceps or intraocular magnet has been considered safer in terms of later vitreoretinal complications. We studied the long term changes in visual acuities of 40 eyes without pars plana vitrectomy at the time of the initial repair. This study focused on magnetic posterior segment IOFB to facilitate comparisons and conclusions regarding treatment for future cases. The aim of this investigation was also the analysis of the visual outcome after magnetic extraction in order to identify the main prognostic factors of final vision.

\section{Patients and methods}

We studied a consecutive series of 40 eyes with posterior segment IOFB removed by electromagnetic extraction from January 1989 to December 1994 (E Herriot Hospital, Lyons, France). Eyes with anterior segment IOFB, scleral or intraretinal IOFB, IOFB removed by vitrectomy techniques, and eyes with double scleral perforations were excluded from the study. Patients with posterior segment magnetic IOFB with no follow up and patients with follow up less than 6 months (10 cases) were also excluded. The analysis also excluded 17 patients because IOFB could not be removed despite the use of a magnetic extractor (nine non-magnetic IOFBs, three scleral IOFBs, one IOFB in the ciliary body, and one in the orbit). Follow up time ranged from 6 to 71 months (mean 30 months). Follow up data were obtained from the outpatient charts and from the referring ophthalmologist when the patient was followed up postoperatively elsewhere.

Preoperative evaluation of patients included a general ophthalmological examination, orbital $x$ rays, and/or computerised axial tomography (CT). The following data were obtained from the records: sex and age of the patient; eye involved; site of initial laceration; the cause of the trauma; the number, type, size, and location of foreign body; preoperative visual acuity (VA); results of external and slit lamp examination; the status of vitreous and retina. The details of surgical procedures were recorded, including time elapsed between injury and IOFB removal, postoperative complications and their treatment. The follow up data included the final best corrected VA, the anterior and posterior complications and duration of follow up.

According to Ryan and Allen's definition, ${ }^{1}$ functional success was defined as preoperative VA of light perception or hand movements improved up to at least $5 / 200$ (according to Snellen chart) or improvement of two lines in those eyes with preoperative Snellen acuity. 
Table 1 Initial ocular findings

\begin{tabular}{lc}
\hline Findings & No of patients (\%) \\
\hline Corneal wound & $23(57.5)$ \\
Scleral laceration & $17(42.5)$ \\
Iris hernia & $5(12.5)$ \\
Iris wound & $13(32.5)$ \\
Hyphaema & $18(45)$ \\
Lens perforation & $15(37.5)$ \\
Vitreous haemorrhage & $18(45)$ \\
Vitreous prolapse & $5(12.5)$ \\
Retinal tear & $1(2.5)$ \\
Retinal detachment & $2(5)$ \\
Retinal impact & $5(12.5)$ \\
\hline
\end{tabular}

Table 2 Visual acuity (VA) in the 40 patients before and after IOFB removal

\begin{tabular}{lll}
\hline Far VA & $\begin{array}{l}\text { No of patients at } \\
\text { admission (\%) } \\
(n=37)\end{array}$ & $\begin{array}{l}\text { No of patients after } \\
\text { surgery }(\%)(n=40)\end{array}$ \\
\hline$<20 / 400$ & $15(37.5)$ & $7(17.5)$ \\
$20 / 400-20 / 80$ & $10(25)$ & $5(12.5)$ \\
$\geqslant 20 / 60$ & $12(30)$ & $28(70)$ \\
\hline
\end{tabular}

Table 3 Ocular complications after retained posterior segment IOFB injury (40 patients)

\begin{tabular}{llc}
\hline Complications & Mean delay (range) & No of patients (\%) \\
\hline Increased IOP & 11 months $(1-25)$ & $3(7.5)$ \\
Traumatic cataract & 11.6 days $(0-130)$ & $24(60)$ \\
$\mathrm{RD}^{\star}$ & 28.8 days $(0-45)$ & $8(20)$ \\
Endophthalmitis & 3 days & $1(2.5)$ \\
Phthysis bulbi & 19 months (4-53) & $3(7.5)$ \\
\hline${ }^{\star}$ Included primary and secondary retinal detachments (RD).
\end{tabular}

Final clinical outcome was defined as poor if VA was less than 20/400. Data were analysed to assess bivariate relation between potential predictors and visual outcome.

SURGICAL TECHNIQUES

On admission, all patients were treated intravenously with antibiotics. Surgical management consisted of repair of the laceration and magnetic extraction of the IOFB in emergency. After a $360^{\circ}$ conjunctival peritomy, the sclera was explored and any corneoscleral wounds were closed with multiple interrupted sutures. A sclerotomy $4 \mathrm{~mm}$ from the limbus was then performed. All foreign bodies were removed with an electromagnet. Following extraction each foreign body was kept.

Additional procedures including pars plana lensectomy and extracapsular cataract extraction were performed in eyes with clinically significant lens opacity. Posterior chamber intraocular lens implantation was performed in certain of these cases. Argon laser photocoagulation around a retinal tear was performed in eyes with relatively clear media and attached retina when indicated. Retinal tears with retinal detachment were localised and treated with cryotherapy. External buckling procedures were then carried out and $\mathrm{C}_{2} \mathrm{~F}_{6}$ gas was used if indicated.

\section{STATISTICAL METHODS}

The studied prognostic factors are listed in Table 4 . Each factor was analysed by $\chi^{2}$ analysis (incorporating Yates's correction) and Student's $t$ test to determine which factors, according to their subgroups, were associated with poor final visual outcome. The Wilcoxon matched pairs signed ranks test permitted comparison of final and initial VA. The null hypothesis was tested using two tailed tests. The statistical analysis was performed using the Statistical Package for the Social Science program (sPss). For better legibility, percentages were rounded to the nearest digit.

\section{Results}

PATIENT BACKGROUND DATA

All 40 patients were men and their age ranged from 12 to 62 years (mean 34 years). There were 19 right eyes (48\%). The average hospital stay was 9 days (4-19 days). The hospitalisation delay after the injury ranged from 1 hour to 3 days in $90 \%$ of the cases. Four patients were consulted 6 days, 15 days, 2 months, and 1 year respectively after the injury.

The injury was caused by use of hammer $(72 \%)$, machine tools $(18 \%)$, or other factors $(10 \%)$. Thirteen $(75 \%)$ of the injuries were work related. The foreign body was single in all cases and varied greatly in shape and size: it was sharp $(52 \%)$, winding $(28 \%)$, angular or round $(20 \%)$. The size of IOFB was defined by largest diameter and ranged from 1 to $25 \mathrm{~mm}$ (mean $4 \mathrm{~mm}$ ).

The commonest ocular findings in the 40 patients at the time of admission are listed in Table 1 . The site of perforation was always single and was frequently the cornea (58\%), followed by the sclera $(32 \%)$, or the cornea and the sclera $(10 \%)$. The corneal wound was central in six patients $(15 \%)$. With regard to the lens, there was a visible through and through injury in 15 cases. Vitreous damage comprised prolapse in five cases and vitreous haemorrhage in 17 cases. Two patients had a retinal detachment present at the initial procedure. On admission, one patient presented with endophthalmitis (septic retinopathy) 3 days after the injury.

Preoperative IOFB localisation was determined by orbital $x$ rays $(52 \%)$ or CT scan $(48 \%)$. Ultrasonography was used for assessing associated intraocular injuries (15\%). The foreign body was minimally embedded in the surface of the retina $(15 \%)$ or located in the vitreous $(85 \%)$.

The preoperative VA in the 40 patients ranged from $20 / 20$ to no light perception (NLP) (Table 2). Preoperative VA was NLP in one patient, hand movements in 13 patients $(33 \%)$, counting fingers in eight patients $(20 \%), 20 / 200$ or more in 15 patients $(37 \%)$, and was not available in three patients. The reason for low initial VA $(<20 / 200)$ in these 22 eyes was retinal damage (three cases), lens damage (10 cases), hyphaema (13 cases), and/or intravitreous haemorrhage (13 cases). In 14 of these cases, IOFB size was $\geqslant 3 \mathrm{~mm}$.

\section{SURGICAL MANAGEMENT}

All 40 foreign bodies were successfully removed during initial surgery. Secondary complete pars plana vitrectomy was performed in nine eyes with a mean delay of 33 days after the primary electromagnetic extraction (range 7-120 days). Pars plana vitrectomy was performed for the following reasons: postoperative 
Table 4 Univariate analysis for 40 eyes with IOFB

\begin{tabular}{|c|c|c|c|}
\hline Factor & No of patients & $\begin{array}{l}\text { Patients with poor visual } \\
\text { outcome (\% or mean for } \\
\text { qualitative variable) }\end{array}$ & p Value \\
\hline Age (years) & 40 & 35.5 (SEM 4.5) & 0.76 \\
\hline Shape of IOFB: & & & 0.18 \\
\hline Sharp & 21 & 2 & \\
\hline Winding & 11 & 4 & \\
\hline Angular or round & 8 & 2 & \\
\hline Largest diameter of IOFB: & & & 0.009 \\
\hline$<3 \mathrm{~mm}$ & 22 & 1 & \\
\hline$\geqslant 3 \mathrm{~mm}$ & 16 & 6 & \\
\hline Largest diameter of IOFB (mm) & 40 & 10 (SEM 3.2) & $<0.001$ \\
\hline IOFB location: & & & 0.37 \\
\hline Vitreous body & 34 & 2 & \\
\hline Retina & 6 & 6 & \\
\hline Entry wound: & & & 0.42 \\
\hline Corneal & 23 & 6 & \\
\hline Corneoscleral & 4 & 0 & \\
\hline Scleral & 13 & 2 & \\
\hline Initial visual acuity: & & & 0.02 \\
\hline$<20 / 200$ & 22 & 8 & \\
\hline$\geqslant 20 / 200$ & 15 & 0 & \\
\hline Initial central corneal wound: & & & 0.55 \\
\hline Yes & 8 & 1 & \\
\hline No & 32 & 7 & \\
\hline Initial scleral wound: & & & 0.7 \\
\hline Yes & 17 & 3 & \\
\hline No & 23 & 5 & \\
\hline Initial hyphaema: & & & 0.26 \\
\hline Yes & 18 & 5 & \\
\hline No & 22 & 3 & \\
\hline Initial prolapse of intraocular tissue: & & & 0.07 \\
\hline Yes & 5 & 3 & \\
\hline No & 35 & 5 & \\
\hline Initial intravitreous haemorrhage: & & & 0.13 \\
\hline Yes & 18 & 6 & \\
\hline No & 22 & 2 & \\
\hline Secondary cataract: & & & 0.07 \\
\hline Yes & 24 & 7 & \\
\hline No & 16 & 1 & \\
\hline Secondary retinal detachment: & & & 0.0001 \\
\hline Yes & 8 & 6 & \\
\hline No & 32 & 2 & \\
\hline
\end{tabular}

retinal detachment (five eyes), epiretinal membranes (one eye), and intravitreous haemorrhage (three eyes).

Management of postoperative retinal detachment required vitreous surgery in five cases. Six eyes received scleral buckling and/or an encircling procedure.

Traumatic cataract required lensectomy using anterior pars plana vitrectomy (14 cases), extracapsular extraction, or phacoemulsification (five cases), with posterior intraocular lens implantation (three cases). No secondary evisceration was performed.

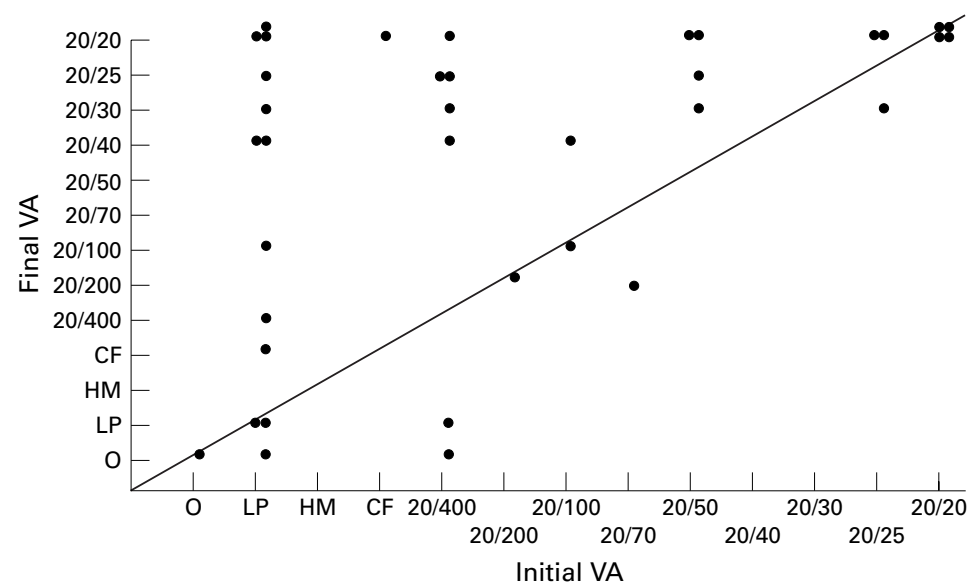

Figure 1 Preoperative visual acuity plotted against postoperative visual acuity (VA) for 37 eyes. The point above the diagonal line represents an improvement in VA.
POSTOPERATIVE COMPLICATIONS (TABLE 3)

Traumatic cataract developed in 24 of 40 eyes $(60 \%)$ with a mean delay of 11 days after the injury (range $0-130$ days). For the 19 operated patients, 13 patients $(68 \%)$ showed a final VA better than or equal to $20 / 200$.

Six patients $(15 \%)$ developed delayed retinal detachment. The interval between trauma and management of retinal detachment ranged from 7 to 45 days after the injury (mean 28 days). In one case the retinal detachment was diagnosed before cataract surgery, and in three cases retinal detachment appeared after the lensectomy. The largest diameter of IOFB $(\geqslant 3 \mathrm{~mm})$ was closely correlated with occurrence of postoperative retinal detachment $(p=0.008)$. In the six patients, size of IOFB ranged from 3 to $11 \mathrm{~mm}$. None of the patients with IOFB $<3 \mathrm{~mm}$ presented such delayed complication. In our series, there was no significant relation between the entry site, IOFB location, retinal impact, IOFB shape, presence of initial intravenous haemorrhage, or cataract and postoperative retinal detachment. This was the largest single cause of blindness in eyes in this series. Final visual acuity was equal to or worse than 20/400 for five of six patients. Retinal detachment surgery included cryopexy and scleral buckling (one case), pars plana vitrectomy-lensectomycryopexy-encircling buckle or pars plana vitrectomy-cryopexy-scleral buckling-gas (five cases). Two patients with initial retinal detachment and NLP were not operated.

One patient presented a septic retinopathy on admission ( 3 days after the injury) but no pathological agents were cultured. Three months later, this patient developed a retinal detachment with vision limited to hand movements. Moreover, no postoperative infection was noted. Three patients developed a chronic increased intraocular pressure treated by local drugs. Phthysis bulbi occurred in three patients with a mean delay of 19 months. No patients developed sympathetic ophthalmia, siderosis, or chalcosis bulb.

\section{VISUAL OUTCOME}

In those cases for which cataract occurred as a late complication, visual functions were evaluated after lens extraction. Ten patients (25\%) had $20 / 200$ or worse vision at the end of their follow up period. In general, 26 eyes (65\%) showed a significant improvement in VA after surgery $(p=0.0001)$ and preoperative VA was retained in another nine $(23 \%)$. Functional success was attained in 23 patients (58\%). Seventy per cent of the patients obtained a final visual acuity better than or equal to 20/40. Figure 1 shows initial (preoperative) VA plotted against final (postoperative) VA.

The most common causes of visual loss (20/ 400 or worse, eight patients) were traumatic cataract (seven eyes), tractional and traumatic retinal detachment (five eyes), or phthysis bulbi (two eyes). Three patients had no light perception (two retinal detachments, one phthysis bulb). In six of the eight patients IOFB size was $3 \mathrm{~mm}$ or more. 
PREDICTIVE FACTORS OF FINAL VISION

Final clinical outcome was defined as poor if final VA was $20 / 400$ or less. Table 4 presented predictors of poor visual outcome identified by univariate analysis. Three variables were predictive of poor visual outcome: (1) largest diameter of IOFB $\geqslant 3 \mathrm{~mm}(\mathrm{p}=0.009)$, (2) initial VA $<20 / 200(p=0.02)$, (3) the presence of initial or secondary retinal detachment $(\mathrm{p}=$ $0.0001)$. If a patient presented a retinal detachment, there was $75 \%$ probability that the final VA would also be worse than 20/400. There was no clear difference in visual outcome between IOFBs located within the vitreous and those adjacent to the retina. The visual outcome was not affected by age of patients, initial scleral wound, corneal wound, hyphaema, lens damage, initial vitreous haemorrhage, tissue prolapse, or traumatic cataract for these 40 patients. When comparing the location of the penetrating wounds classified as corneal, corneoscleral, or scleral, no association with visual outcome was found. The statistical evaluation demonstrated no significant difference in the final visual acuity as a function of the time of the primary surgery.

\section{Discussion}

Posterior segment IOFB trauma with severe eye injury carries a poor visual prognosis and continues to present a bewildering array of management decisions. Results of IOFB surgery with and without vitrectomy have been presented by several authors. Endovitreal microsurgery and electromagnetic extraction offer different treatment possibilities for the removal of IOFBs. Many factors influence ultimate visual recovery. These include the size, material, and location of the IOFB; the associated ocular injuries; and the development and management of late complications after IOFB removal. The primary method of extraction is currently controversial because comparisons between statistics are critical owing to the diversity of patient injuries and to selection bias. Our case series report describes the clinical outcome using magnetic extraction. Indeed, magnetic removal was systematically attempted in all subjects if the IOFB appeared magnetic, preretinal, or within the vitreous. No cases had primary vitrectomy unless magnetic extraction had previously failed. Because of the relatively small number of cases with certain categories of clinical variables, it was not possible to develop any logistic regression model.

The causative agents were use of hammer in $72 \%$ of cases, while $10 \%$ of the trauma were caused by machine tools. As reported by Roperhall, ${ }^{2}$ Hadden and Wilson, ${ }^{3}$ and BehrensBaumann and Praetorius, ${ }^{4}$ hand hammer injuries were the commonest cause and were due to a work related activity. Industrial and agricultural accidents were the main circumstances in which the injuries with magnetic IOFB occurred. Our data indicate the importance of wearing protective goggles when working with a hammer.

A recent multivariate analysis ${ }^{5}$ showed that age was a significant factor in eyes with IOFBs and that patients 18 years or older had better visual outcomes. In our series, the number of young patients was too small (six cases) to correlate by the age of patients.

The removal failures with an electromagnet illustrated the importance of determining the IOFB type and of the accuracy of foreign body localisation. Whereas $x$ rays remain the most sensitive method for defeating metallic foreign bodies, ultrasonography and CT scans are of value in selected cases. ${ }^{6}$ CT scanning can localise a foreign body with reference to the sclera. Moreover, CT evaluation of penetrating ocular trauma can be used to predict functional and anatomical outcome in eyes with penetrating injuries. ${ }^{7}$ For six patients, diagnostic echography provided useful prognostic information in eyes with media opacity. Indeed, preoperative echography appears both sensitive and specific in evaluating traumatised eyes. ${ }^{8}$ In our series, several IOFBs were minimally embedded in the retina but not deeply located in the retina and the choroid. In such cases, which were excluded from our analysis, we preferred to use intraocular forceps.

In our study, 23 of 40 subjects (58\%) achieved functional success according to Ryan and Allen's definition. ${ }^{1}$ Twenty eight of 40 patients $(70 \%)$ obtained a final VA better than $20 / 60$. These results are similar to recent studies, ${ }^{39}$ in which electromagnetic extraction was performed. Hadden and Wilson ${ }^{3}$ reported 28 of 38 patients $(73.6 \%)$ with final VA better than or equal to $20 / 60$. Respectively, this success was obtained in 11 of 13 patients $(87 \%)$ in Punnamen and Laatikainen's study. ${ }^{9}$ Whatever the method of extraction, outcome of IOFB cases varies; percentages of patients with final VA better than or equal to $20 / 60$ range from $39.3 \%$ to $66 \%$ in several studies. ${ }^{210-12}$ However, comparison of the long term results of various IOFB extraction techniques remains difficult because of considerable diversity of traumatism. For example, Punnamen and Laatikainen ${ }^{9}$ and Williams et $a l^{12}$ have found no statistically significant difference in visual outcome between eyes that underwent primary magnetic extraction and those that underwent primary pars plana vitrectomy with foreign body removal (by forceps). In penetrating ocular trauma, Esmaeli et $a l^{13}$ and De Juan et al ${ }^{14}$ showed no statistical advantage over vitrectomy. However, beneficial trends of vitrectomy were demonstrated in air rifle, double penetration, or other severe injuries with initial VA worse than $5 / 200 .^{14}$

Several reports ${ }^{912}$ suggested that the visual outcome of eyes with IOFBs was unfavourably affected by posterior location of the perforation, blunt injury, prolapse of intraocular tissue, a wound $4 \mathrm{~mm}$ or longer in length, or a poor initial VA. Our study included only patients who had primary repair of the wound and magnetic extraction, which probably reduced the selection bias associated with referral of patients for secondary surgery. Factors found to be associated with poor final vision (20/400 or less) in posterior segment IOFB removed by electromagnet were initial 
vision less than 20/200, an IOFB $3 \mathrm{~mm}$ long or more, and presence of post-traumatic retinal detachment.

Consistent with previous clinical series, we found that initial visual acuity is an important prognostic indicator of visual outcome after penetrating trauma ${ }^{5^{13-18}}$ and after IOFB trauma. ${ }^{1219}$

Several authors stress the prognostic value of IOFB size. Roper-Hall ${ }^{2}$ showed that the size and the weight of IOFBs were the most important factors in the prognosis. Percival ${ }^{10}$ and Johnston $^{20}$ related that the visual prognosis deteriorates with increasing size, confirmed by the high excision rate associated with a large IOFB (respectively larger than 15 or $20 \mathrm{~mm}^{3}$ ).

In our study, the entrance wound characteristics did not appear predictive of visual outcome. Punnamen and Laatikainen ${ }^{9}$ observed that $70 \%$ of eyes with a posterior segment perforation became blind compared with only $20 \%$ with an anterior segment perforation. However, Williams et al ${ }^{12}$ did not find a predictive value of the location of the wound although a wound size of $4 \mathrm{~mm}$ or greater was predictive of a poor visual outcome.

Cataract was common $(60 \%, 24$ patients) and lens extraction required surgery in 19 of the 24 patients in our study $(79 \%)$. According to several reports, ${ }^{11}{ }^{19-24}$ traumatic cataract occurs in $36 \%$ to $69 \%$ of the cases. Secondary cataract had no significant effect on the final visual results in our analysis, as reported by other authors..$^{912}{ }^{15}$ In general, surgical therapy improves visual outcome for lens opacity and is not predictive of poor vision. Indeed, 13 of 19 patients $(68 \%)$ in our series, achieved a final VA better than or equal to $20 / 200$ and functional success was achieved for 11 patients $(58 \%)$. The poor functional visual outcome of four patients (final VA $\leqslant 20 / 400$ ) can be explained by secondary retinal detachment.

The presence of intravitreous haemorrhage was not correlated with the visual outcome but our retrospective study did not allow precise quantification of this factor. According to several reports, ${ }^{1525}{ }^{26}$ severe intravitreous haemorrhage was predictive of a poor prognosis. The analysis of these factors emphasises that visual outcome is strongly influenced by the nature of the penetrating trauma and the extent of initial wounds.

Preoperative and postoperative retinal detachments were important factors with therapeutic and prognostic implications, as previously reported. ${ }^{1927} 28$ In our series postoperative retinal detachment occurred in $15 \%$ of eyes and these patients did not present an initial retinal tear. These patients underwent a conventional or a vitreoretinal surgery and obtained a final visual acuity less than $20 / 400$ in $71 \%$ of the cases. Other authors reported $8 \%-17 \%$ after magnetic extraction. ${ }^{31129}{ }^{30}$ Two multivariate analyse ${ }^{17} 26$ demonstrated that retinal detachment had a poorer prognosis in severe ocular trauma. Percival ${ }^{24}$ noted $22 \%$ of eyes with postoperative retinal detachment and found four essential risk factors: intravitreous haemorrhage (odds ratio (OR) 8.4), foreign body size over $1 \mathrm{~mm}^{3}$ (OR 4.5), transvitreous manipulation (OR 1.8), and vitreous loss (OR 1.7). The number of patients in our series allowed a univariate analysis determining the largest diameter of IOFB ( $\geqslant 3 \mathrm{~mm}$ ) as an indicator of postoperative retinal detachment. Retinal impact injury, entry site, initial intravenous haemorrhage, or tissue prolapse did not appear significantly correlated to secondary retinal detachment. Because of the small number of retinal detachments in our series of 40 patients, other potential risk factors should be analysed a multivariate analysis with a larger sample. Intravitreous haemorrhage was reported to be associated with intraocular proliferation and traction detachment of retina in experimental studies ${ }^{18}{ }^{31-34}$ and clinical studies. ${ }^{18} 202435$ A controlled trial in the rhesus monkey suggested that both core and complete vitrectomies prevented development of traction retinal detachment after experimental posterior penetrating eye injury. ${ }^{36}{ }^{37}$ However, ocular trauma with IOFB can be a complex situation and differs from the above experimental vitrectomy with clean surgical incision. In our experience, surgeons prefer the use of electromagnetic extraction whenever possible in posterior segment IOFB regardless of the presence of small or moderate vitreous haemorrhage, whereas pars plana vitrectomy is reserved for non-magnetic IOFB, intraretinal or encapsulated IOFB, dense vitreous haemorrhage, and management of late complications. Moreover, primary extraction with vitrectomy in emergency can be difficult and sometimes iatrogenic because of the absence of posterior vitreous detachment, risk of bleeding, and accidental retinal tear. The primary usefulness of the pars plana vitrectomy appears interesting in cases with dense vitreous haemorrhage and risk factors of secondary tractional retinal detachment to control or prevent the pathogenesis of traction retinal detachment. Management of secondary complications related to intraocular fibrous proliferation, cyclitic membrane formation and vitreoretinal traction with retinal detachment must involve secondary vitrectomy.

Several authors ${ }^{11} 122138$ continue to use the external magnet in the presence of clear ocular media. On analysis of our results and after review of the literature, we considered that the magnet remains a useful technique in emergency but its indication must be restricted in order to avoid side effects and failure of removal. In the most suitable cases, this technique can reduce IOFB manipulation. On the basis of our own experience, it emerges that a patient with a small foreign body $(<3 \mathrm{~mm})$ located in the vitreous or minimally embedded in the retina with an initial VA $\geqslant 20 / 100$ remains a good candidate for primary external magnet extraction.

1 Ryan SJ, Allen AW. Pars plana vitrectomy in ocular trauma. Am F Ophthalmol 1979;88:483-91.

2 Roper-Hall MJ. Review of 555 cases of intraocular foreign body with special reference to prognosis. $\mathrm{Br} \mathcal{F}$ Ophthalmol 1954;38:65-99.

3 Hadden OB, Wilson JL. The management of intraocular foreign bodies. Aust NZ F Ophthalmol 1990;18:343-51.

4 Behrens-Baumann W, Praetorius G. Intraocular foreign Behrens-Baumann W, Praetorius G. Intraocular foreign
bodies. 297 consecutive cases. Ophthalmologica 1989;198: 84-8. 
5 Sternberg P, De Juan E, Michels RG, et al. Multivariate analysis of prognostic factors in penetrating ocular injuries

6 Rodman Irvine A. Old and new techniques combined in the management of intraocular bodies. Ann Ophthalmol 1981; 13:47

7 Maguire AM, Enger C, Eliott D, et al. Computerized tomography in the evaluation of penetrating ocular injuries. Retina 1991;11:405-11.

8 Rubsamen PE, Cousins SW, Winward KE, et al. Diagnostic ultrasound and pars plana vitrectomy in penetrating ocula trauma. Ophthalmology 1994;101:809-14.

9 Punnamen E, Laatikainen L. Prognosis of perforating eye injuries with intraocular foreign bodies. Acta Ophthalmol 1989;67:483-91.

10 Percival SPB. A decade of intraocular foreign bodies. $\mathrm{Br} F$ Ophthalmol 1972;56:454-61.

11 Coleman DJ, Lucas BC, Rondeau MJ, et al. Management of intraocular foreign bodies. Ophthalmology 1987;94:1647intraoc

12 Williams DF, Mieler WF, Abrams GW, et al. Results and prognostic factors in penetrating ocular injuries with retained intraocular foreign bodies. Ophthalmology 1988, 95:911-16.

13 Esmaeli B, Elner SG, Schork MA, et al. Visual outcome and ocular survival after penetrating trauma. Ophthalmology 1995;102:393-400

14 De Juan E, Sternberg P, Michels RG, et al. Evaluation of vitrectomy in penetrating ocular trauma: a case control study. Arch Ophthalmol 1984;102:1160-3.

15 De Juan E Jr, Sternberg P, Michels RG. Penetrating ocular injuries: types of injuries and visual results. Ophthalmology 1983;90:1318-22.

16 Gilbert CM, Soong HE, Hirst LW. A two-year prospective study of penetrating ocular trauma at the Wilmer Ophthalmological Institute. Ann Ophthalmol 1987;19:104-6.

17 Hutton WL, Fuller DG. Factors influencing final visual results in severely injured eyes. Am f Ophthalmol 1984;97: results in $715-22$.

18 Eagling EM. Perforating injuries involving the posterior segment. Trans Ophthalmol Soc UK 1975;95:335.

19 19. Howcroft MJ, Shea M. Management of posteriorsegment foreign bodies. Can 7 Ophthalmol 1982;17:25661 .

20 Johnston S. Perforating injuries: a five year study. Trans Ophthalmol Soc UK 1971;91:895-920.

21 Shock JP, Adams D. Long term visual acuity results after penetrating and perforating ocular injuries. Am f Ophthalmol 1985;100:714

22 Kazokoglu H, Saatci O. Intraocular foreign bodies: results of 27 cases. Ann Ophthalmol 1990;22, 10:373-6.
23 Neill E, Eagling EM. Intraocular foreign bodies: indications for lensectomy and vitrectomy. Trans Ophthalmol Soc UK 1978;98:47-8.

24 Percival SPB. Late complications from posterior segment intraocular foreign bodies. Br f Ophthalmol 1972;56:462-8.

25 Ahmadieh $\mathrm{H}$, Soheilian M, Sajiadi $\mathrm{H}$, et al. Vitrectomy in ocular trauma. Factors influencing final visual outcome. Retina 1993;13:107-13.

26 Brinton GS, Aaberg TM, Reeser FH, et al. Surgical results in ocular trauma involving the posterior segment. $A m \mathcal{F}$ Ophthalmol 1982;93:271-8.

27 Heimann K, Paulmann H, Tavakoli U. The intraocular foreign body: principles and problems in the management of complicated cases by pars plana vitrectomy. Int Ophthalmol 1983;6:235-42.

28 Camacho H, Mejia LF. Extraction of intraocular foreign bodies by pars plana vitrectomy. A retrospective study. Ophthalmologica 1991;202:173-9.

29 Arciniegas A, Araya R. Our experience in intraocular foreign-body removal. Ann Ophthalmol 1992;24:453-8.

30 Karel I, Diblik P. Management of posterior segment foreign bodies and long-term results. Eur f Ophthalmol 1995;5: 113-18.

31 Winthrop SR, Cleary PE, Minckler DS, et al. Penetrating eye injuries: a histopathological review. $\mathrm{Br} \mathcal{F}$ Ophthalmol 1980;64:809-17.

32 Coles WH, Haik GM. Vitrectomy in intraocular trauma. Its rationale and its indications and limitations. Arch Ophthalmol 1972;87:621-8.

33 Clearly PE, Ryan SJ. Experimental posterior penetrating eye injury in the rabbit: II. History of wound, vitreous and retina. Br f Ophthalmol 1979;63:312-21.

34 Cleary PE, Ryan SJ. Method of production and natural history of experimental posterior penetration eye injury in the rhesus monkey. Am f Ophthalmol 1979;88:212-20.

35 Faulborn J, Atkinson A, Olivier D. Primary vitrectomy as a preventive surgical procedure in the treatment of severely injured eyes. Br F Ophthalmol 1977;61:202-8.

36 Gregor Z, Ryan SJ. Complete and core vitrectomies in the treatment of experimental posterior penetrating eye injury in the rhesus monkey. I Clinical features. Arch Ophthalmol 1983;101:441-5.

37 Gregor Z, Ryan SJ. Complete and core vitrectomies in the treatment of experimental posterior penetrating eye injury in the rhesus monkey. I Histologic features. Arch Ophthalmol 1983;101:446-50.

38 Michels RG. Vitrectomy methods in penetrating ocular trauma. Ophthalmology 1980;87:629-45. 